\title{
OPTIMIZATION AND CHARACTERIZATION OF PEG-PCL-PEG TRIBLOCK COPOLYMER AS CARRIER OF DRUG USING FULL FACTORIAL DESIGN
}

\author{
ZYNOPSICHA ARMATAZAKA ${ }^{1}$, T. N. SAIFULLAH SULAIMAN", ABDUL KARIM ZULKARNAIN² \\ ${ }^{1}$ Faculty of Pharmacy, Gadjah Mada University, Yogyakarta 55281 Indonesia, ${ }^{2}$ Departement of Pharmaceutics, Faculty of Pharmacy, \\ Gadjah Mada University, Yogyakarta 55281 Indonesia \\ Email: tn.saifullah@gmail.com
}

Received: 17 May 2019, Revised and Accepted: 16 Jul 2019

\begin{abstract}
Objective: Triblock copolymer of poly(ethylene glycol)-poly( $\varepsilon$-caprolactone)-poly(ethylene glycol) (PEG-PCL-PEG, PECE) was applicated as hydrophobic drug. This study aims to optimization and characterization of PECE triblock copolymer as carriers of hydrophobic drug (ketoprofen).

Methods: Triblock copolymer of PECE was prepared with varying composition ratio of PEG and PCL by ring-opening and coupling reaction. The characteristics of triblock copolymer were characterized using FTIR and DSC. Variation composition ratio of poly( $\varepsilon$-caprolactone) (PCL)/poly(ethylene glycol) (PEG) and ratio PECE/drug as factors for optimization using full factorial design. Ketoprofen was loaded into PECE triblock copolymer micelles by emulsification and solvent evaporation method. Responses were measured particle size, entrapment efficiency (EE) and drug solubility.
\end{abstract}

Results: The result of this study showed that a higher ratio of PCL/PEG and ratio of PECE/drug, reducing particle size, increasing EE and improving drug solubility. The optimum formula obtained by ratio of PCL/PEG is 2:1 and ratio of PECE/drug is 40:1 with particle size is $356,967 \pm 9,142 \mathrm{~nm}$, EE is $57,751 \pm 0,437 \%$, drug solubility is $32,648 \pm 0,200 \mu \mathrm{g} / \mathrm{ml}$ and zeta potential- $18,867 \pm 2,578 \mathrm{mV}$. A full factorial design was applied to determine the optimum formula for the PECE triblock copolymer as drug carriers.

Conclusion: The PECE triblock copolymer was preparated using ring-opening polymerization method with $\operatorname{Sn}(0 \mathrm{ct})_{2}$ as a catalyst and then continued the reaction with HMDI as coupling agent. Ketoprofen was loaded into PECE triblock copolymer using methods emulsification and solvent evaporation.

Keywords: Ketoprofen, Triblock copolymer, PCL PEG, Full Factorial

(C) 2019 The Authors. Published by Innovare Academic Sciences Pvt Ltd. This is an open-access article under the CC BY license (http://creativecommons.org/licenses/by/4.0/) DOI: http://dx.doi.org/10.22159/ijcpr.2019v11i5.35706

\section{INTRODUCTION}

The polymers used in drug formulations is biodegradable polymers that mean they can be degraded by metabolic reaction in the body. Polymer in drug formulation can be used in the form of triblock copolymer. Biodegradable polymers that can be used in drug delivery such as poly( $\varepsilon$-Caprolactone) (PCL) and poly(ethylene glycol) (PEG) [1]. Triblock copolymers have advantages such as can be applied as a carrier of hydrophilic or hydrophobic drugs, can be varied arrangement of polymer blocks, and can be used for improving drug solubility or controlling drug release [2]. The application of triblock copolymer with the composition of PCL and PEG has existed previously as drug delivery system of drug that has a low solubility (hydrophobic). The triblock copolymer will take the hydrophobic drug into aqueous by forming a nano-sized polymer micelle spontaneously. The hydrophilic block will interact with aqueous solution while the hydrophobic block will be the core-shell that contains hydrophobic drugs so can increase the solubility of the drug [3].

Ketoprofen is a nonselective non-steroid anti-inflammatory (NSAID) drug used for a mild to moderate pain relievers such as pain in dysmenorrhea, headache, osteoarthritis and rheumatoid arthritis. Ketoprofen has low solubility properties about $0,010 \mathrm{mg} / \mathrm{ml}$ in pure water at $\left(22-24{ }^{\circ} \mathrm{C}\right)$ and high permeability with $\log P$ value is 3,31 . The calculation of dose per solubility (D/S) with the dose is $100 \mathrm{mg}$ obtain that $10 \mathrm{~L}(>250 \mathrm{ml}$ ) of water was needed to dissolve the dose of drug. Based on that physicochemical properties the drug including in class II of Biopharmaceutical Classification System (BCS) according to WHO [4]. Therefore, ketoprofen can be used as a model of hydrophobic drugs.

The aim of this study is to optimization and characterization of PEGPCL-PEG (PECE) triblock copolymer as ketoprofen drug delivery system. PECE triblock copolymer is an analog of commercial polymer that is Poloxamer (PEO-PPO-PEO). Poloxamer has weakness such as non-biodegradable polymer, its mean that polymer does not can be degraded in the body so can cause of toxicity [2]. PECE triblock copolymer expected to be safer to use in drug formulation and has a potential for drug delivery system, so need to be done optimum formula to form a PECE triblock copolymer. In addition, it aims determine the influence of variation ratio of PCL/PEG and ratio of PECE/drug on particle size, EE and drug solubility mathematically with factorial design.

\section{MATERIALS AND METHODS}

\section{Materials}

Methoxy-poly (ethylene glycol) $\sim 2000$ (mPEG $\sim 2000$ ), $\varepsilon$ caprolactone ( $\varepsilon-\mathrm{CL})$, hexamethylene diisocyanate (HMDI), stannous octoate $\left(\mathrm{Sn}(\mathrm{Oct})_{2}\right)$, petroleum ether and dichloromethane was purchased from Sigma-Aldrich (Singapore), Ketoprofen (PT. Combiphar, Bandung, Indonesia).

\section{Methods}

Preparation of the PEG-PCL-PEG (PECE) triblock copolymer: PECE triblock copolymers were prepared by ring-opening polymerization of $\varepsilon$-CL using $\mathrm{Sn}(\mathrm{Oct})_{2}$ as catalyst and continued by coupling reaction using HMDI as coupling agent is illustrated in fig. 1. In the first step amount of $\mathrm{mPEG}, \varepsilon-\mathrm{CL}$, and $\mathrm{Sn}(\mathrm{Oct})_{2}$ were introduced into a $50 \mathrm{ml}$ filter flask under vacuum. The mixture was reacted with magnetic stirrer at $120^{\circ} \mathrm{C}$ for $6 \mathrm{~h}$. After that HMDI was added into the mixture and continued the reaction at $80^{\circ} \mathrm{C}$ for $6 \mathrm{~h}$. After reaction, the results obtained was purified with dissolved in dichloromethane and then precipitated with cold petroleum ether. Purification was repeated twice. The PECE triblock copolymer was dried in room temperature after that dried polymer was storage in airtight container [5]. 


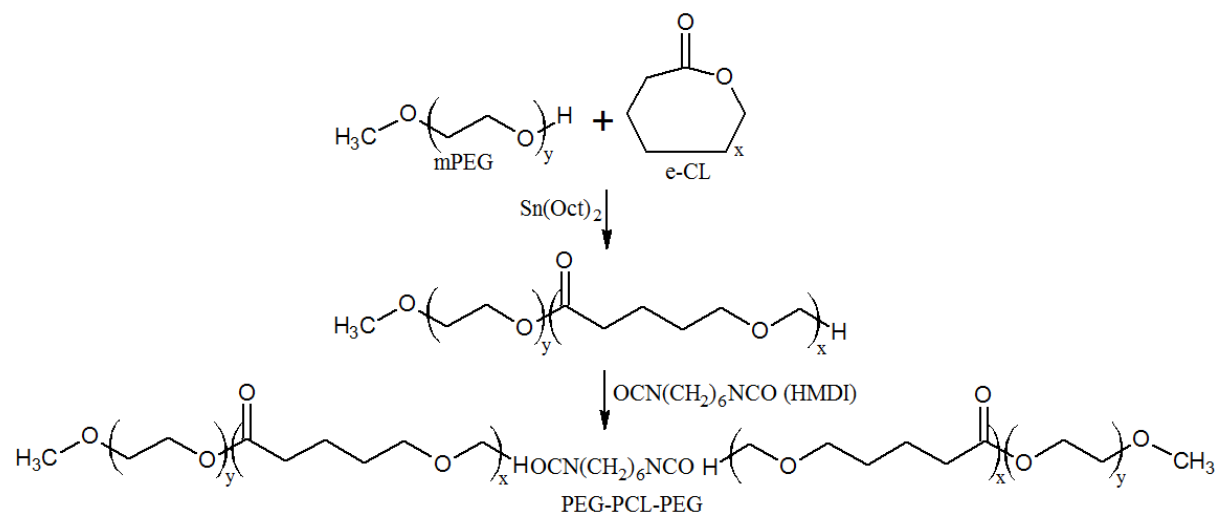

Fig. 1: Schematic formation of the PECE triblock copolymer

Preparation of the PECE triblock copolymer loaded ketoprofen: Weighed as much as $10 \mathrm{mg}$ of ketoprofen and PECE polymer was subsequently dissolved in dichloromethane. Then added $100 \mathrm{ml}$ water to form emulsions. Emulsions are stirred at $25^{\circ} \mathrm{C}$ to dichloromethane evaporated perfectly. The solution was then centrifuged with a speed of $4000 \mathrm{rpm}$ for $1 \mathrm{~h}$. Deposits have been rinsed with water 2 times.
Full factorial design for optimization: The experimental design used is full factorial design with 2 levels of low (-1) and high (1) and 2 factors $\left(2^{2}\right)$. The factors used are the ratio of PCL/PEG $\left(\mathrm{X}_{1}\right)$ and ratio of PECE/drugs $\left(\mathrm{X}_{2}\right)$. Tests used in response include particle size $\left(\mathrm{Y}_{1}\right)$, entrapment efficiency $(\mathrm{EE})\left(\mathrm{Y}_{2}\right)$ and drug solubility $\left(\mathrm{Y}_{3}\right)$ (table 1) $[6,7]$.

Table 1: Factorial design for optimization PECE triblock copolymer

\begin{tabular}{|c|c|c|c|}
\hline \multirow[t]{2}{*}{ Code } & \multirow[t]{2}{*}{ Factors } & \multicolumn{2}{|l|}{ Level } \\
\hline & & Low (-1) & High (1) \\
\hline $\mathrm{X}_{1}$ & Ratio of PCL/PEG & 0,5 & 2 \\
\hline $\mathrm{X}_{2}$ & Ratio of PECE/drug & $10: 1$ & $40: 1$ \\
\hline \multicolumn{2}{|c|}{ Responses } & \multicolumn{2}{|l|}{ Target } \\
\hline$Y_{1}$ & Particle size (nm) & \multicolumn{2}{|l|}{ Minimize } \\
\hline $\mathrm{Y}_{2}$ & Entrapment efficiency (EE) (\%) & \multicolumn{2}{|l|}{ Maximize } \\
\hline $\mathrm{Y}_{3}$ & Drug solubility $(\mu \mathrm{g} / \mathrm{ml})$ & \multicolumn{2}{|l|}{ Maximize } \\
\hline
\end{tabular}

\section{Characterization of PECE triblock copolymer}

The structure of $\mathrm{mPEG}_{2000,} \varepsilon-\mathrm{CL}$, and formation of triblock copolymer were confirmed by Fourier Transform Infrared Spectroscopy (FTIR) Nicolet iS10 in a wavelength range of $500-4000 \mathrm{~cm}^{-1}$ [8]

The thermal analysis by Differential Scanning Calorimetry (DSC) on the sample of triblock copolymer. Samples were given temperature treatment starting from $26^{\circ} \mathrm{C}$ temperature to be heated to $90^{\circ} \mathrm{C}$. Temperature change speed of $10^{\circ} \mathrm{C} / \mathrm{min}[5]$.

\section{Measurement responses for optimization:}

\section{Particle size and zeta potential measurement}

PECE triblock copolymer loaded ketoprofen was dissolved in water and stirring for $1 \mathrm{~h}$. The solution taken and measured particle size and zeta potential using Particle Sizer Analyzer (PSA) at $25^{\circ} \mathrm{C}$ and scattering angle 90 .

\section{Measurement of entrapment efficiency (EE)}

Weighed $10 \mathrm{mg}$ of ketoprofen and PECE triblock copolymer was subsequently dissolved with dichloromethane. Solution added 100 $\mathrm{ml}$ of water slowly and stirring until dichloromethane evaporated. The solution is filtered with filter until $1 \mathrm{ml}$ is obtained. The solution added $\mathrm{NaOH} 0.1 \mathrm{~N}$ to $10 \mathrm{ml}$ and then read the absorbance with UVVis spectrophotometer at the maximum wavelength of ketoprofen. The calculation of entrapment efficiency is following equation: ((Initial concentration of drug-Concentration of drug was measured)/Initial concentration of drug) x100\%.

\section{Measurement of drug solubility}

PECE triblock copolymer was loaded ketoprofen with certain comparison is dissolved with $100 \mathrm{ml}$ water. The solution was stirring for $24 \mathrm{~h}$ at a speed of $60 \mathrm{rpm}$. The solution was taken and added $\mathrm{NaOH} 0.1 \mathrm{~N}$ to $10 \mathrm{ml}$ and then read the absorbance with UVVis spectrophotometer at the maximum wavelength of ketoprofen.

\section{RESULTS AND DISCUSSION}

\section{Preparation of the PEG-PCL-PEG (PECE) triblock copolymer}

PECE triblock copolymer was prepared by 2 stages of reactions. The first reaction is the ring opening reaction on $\varepsilon$-CL structure with the $\mathrm{Sn}(\mathrm{Oct})_{2}$ as catalyst and the merger with $\mathrm{mPEG}$ resulting PEG-PCL diblock copolymer. Second reaction that is coupling reactions blocked PEG-PCL with a coupling agent HMDI so formed PEG-PCLPEG triblock copolymer. Based on the factorial design (table 1) that the PECE triblock copolymer was prepared with PCL/PEG ratio of 0.5:1 and 2:1, and PECE/drug ratio of 10:1 and 40:1. PECE triblock copolymer which resulting is a form white coarse powder.

\section{Characteristics of PECE triblock copolymer}

Chemical characterization with FTIR aims to confirm the formation of PECE triblock copolymer structure. The result of characterization by FTIR is presented in fig. 2. Spectra FTIR (a) is a spectra of $\varepsilon$-CL. This spectra show there are functionally groups of hydrocarbons and a carboxylic acid. The result of the hydrocarbon functional group is that there is a peak on the wavenumber $2933.54 \mathrm{~cm}^{-1}, 2862.85 \mathrm{~cm}^{-1}$ and $733.35 \mathrm{~cm}^{-1}$ because of vibration strain asymmetrical and symmetrical from $\mathrm{CH}_{2}$ and vibration from swings chains hydrocarbons, respectively. In addition, there is a peak at $1476.30 \mathrm{~cm}^{-1}$ and 1438.00 $\mathrm{cm}^{-1}$ because of vibration deformation $\mathrm{CH}_{3}$ and vibration asymmetrical $\mathrm{CH}_{2}$ scissor, respectively. While functional group of carboxylic acid show at around $3300-2500 \mathrm{~cm}^{-1}$ for $\mathrm{O}-\mathrm{H}$ group, at $1723.19 \mathrm{~cm}^{-1}$ for $\mathrm{C}=$ O group, on $1288.78-1224.76 \mathrm{~cm}^{-1}$ for C-O group, and on 961.29 $890.98 \mathrm{~cm}^{-1}$ for deformation O-H group [9].

Spectra (b) is a spectra from a single polymer $\mathrm{mPEG}_{2000}$. This spectra show there is a peak in the around at $3400-3600 \mathrm{~cm}^{-1}$, that is characteristic of group hydroxyl terminal on the structures. In addition, there is a peak at $2880.81 \mathrm{~cm}^{-1}$ and $1098.57 \mathrm{~cm}^{-1}$, that is characteristics from group $\mathrm{C}-\mathrm{H}$ and $\mathrm{C}-\mathrm{O}$ on the structures [9]. 


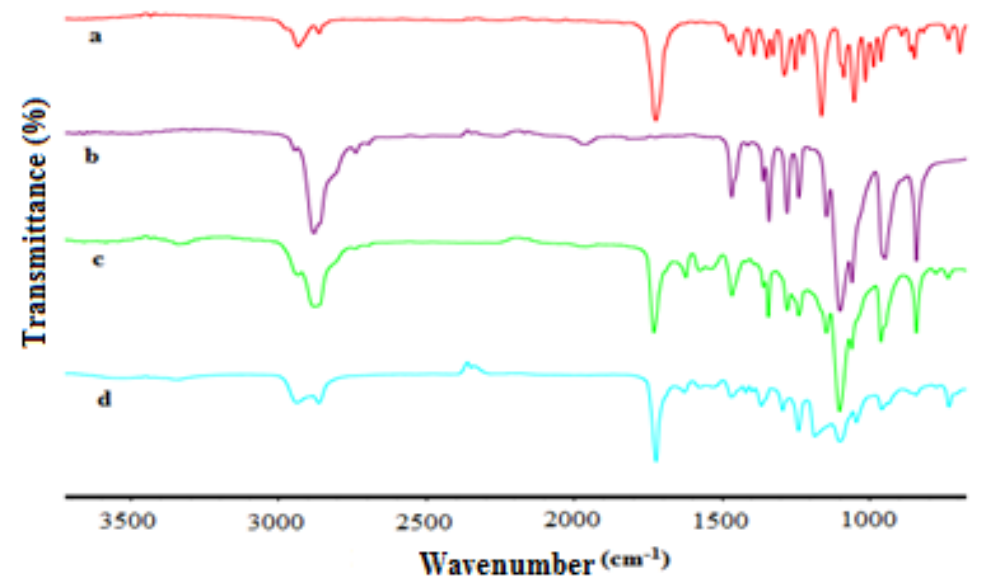

Fig. 2: Spectra FTIR of (a). $\varepsilon$-CL, (b). mPEG2000, (c). PECE triblock copolymer 0.5:1, and (d). PECE triblock copolymer 2:1

Spectra of the triblock copolymer is shown on spectra (c) and (d). PECE triblock copolymer ratio of PCL/PEG is $0.5: 1$ shown on the spectra (c) indicating that there is a peak at $2877.62 \mathrm{~cm}^{-1}$ that occur because asymmetric of the $\mathrm{CH}_{3}$ group. The peak at $1239.25 \mathrm{~cm}^{-1}$ and $1101.57 \mathrm{~cm}^{-1}$ for C-O-C group strain vibration and the COO group, respectively. The stretch vibrations of the $\mathrm{C}=0$ group appear at $1730.29 \mathrm{~cm}^{-1}$ which is the characteristic of the ester group. While the spectra (d) is the PECE triblock copolymer ratio of PCL/PEG is 2:1 The spectra shows that there is a peak at $2937.59 \mathrm{~cm}^{-1}$ and 2864.29 $\mathrm{cm}^{-1}$ for asymmetric and symmetrical strain of the $\mathrm{CH}_{2}$, respectively. In addition, there is a peak at $1100.54 \mathrm{~cm}^{-1}$ and $1363.36 \mathrm{~cm}^{-1}$ that indicate there is a vibration strain of $\mathrm{C}-\mathrm{O}-\mathrm{C}$ group and $\mathrm{COO}$ group. There is a peak at $1722.08 \mathrm{~cm}^{-1}$ which occurs due to a group strain of $\mathrm{C}=0$. The both of spectra do not have peak at $2250 \mathrm{~cm}^{-1}-2270 \mathrm{~cm}$ ${ }^{1}$ which is characteristic that the NCO group structure of the HMDI compounds reacts perfectly with the $\mathrm{OH}$ group on the reaction. There is a peak at $1576.15 \mathrm{~cm}^{-1}$ in PECE triblock copolymer ratio of $0.5: 1$ and $1574.97 \mathrm{~cm}^{-1}$ on ratio of $2: 1$ is characteristic of the $\mathrm{N}-\mathrm{H}$ group vibration as a sign that the formation of PECE triblock copolymer [9].
The characterization of thermal analysis of the PECE triblock copolymer is carried out with the Differential Scanning calorimetry (DSC). Analyses thermal aims to do find out the melting point of triblock copolymer. The thermal analysis curve (DSC) is shown in fig. 3.

The (a) and (b) curves are the thermal curves of mPEG2000 and $\varepsilon$-CL. Both curves indicate that there is only a single peak melting point of the compound that is at temperatures $53.34^{\circ} \mathrm{C}$ and $37.66{ }^{\circ} \mathrm{C}$ that each is a melting point of the compound mPEG2000 and $\varepsilon$-CL. The (c) and (d) curves are the thermal curves of the PECE triblock copolymer with a ratio of PCL/PEG are 0.5:1 and 2:1. The thermal curve of the PECE triblock copolymer indicates the existence of 2 peaks of melting point temperature although the peak is not clearly separated. The low melting point temperature of both curves is at $50.98^{\circ} \mathrm{C}$ and $45.64{ }^{\circ} \mathrm{C}$, which is the temperature of the melting point of the PCL block in the crystal phase and the high melting point temperature peak is at $54.78{ }^{\circ} \mathrm{C}$ and $53.81^{\circ} \mathrm{C}$ as melting point for the $\mathrm{MPEG}$ block in the crystal phase. The thermal properties of a single polymer and the PECE copolymer triblock that produce curves with a single peak and multiple-peak are also reported in previous studies $[8,10]$.
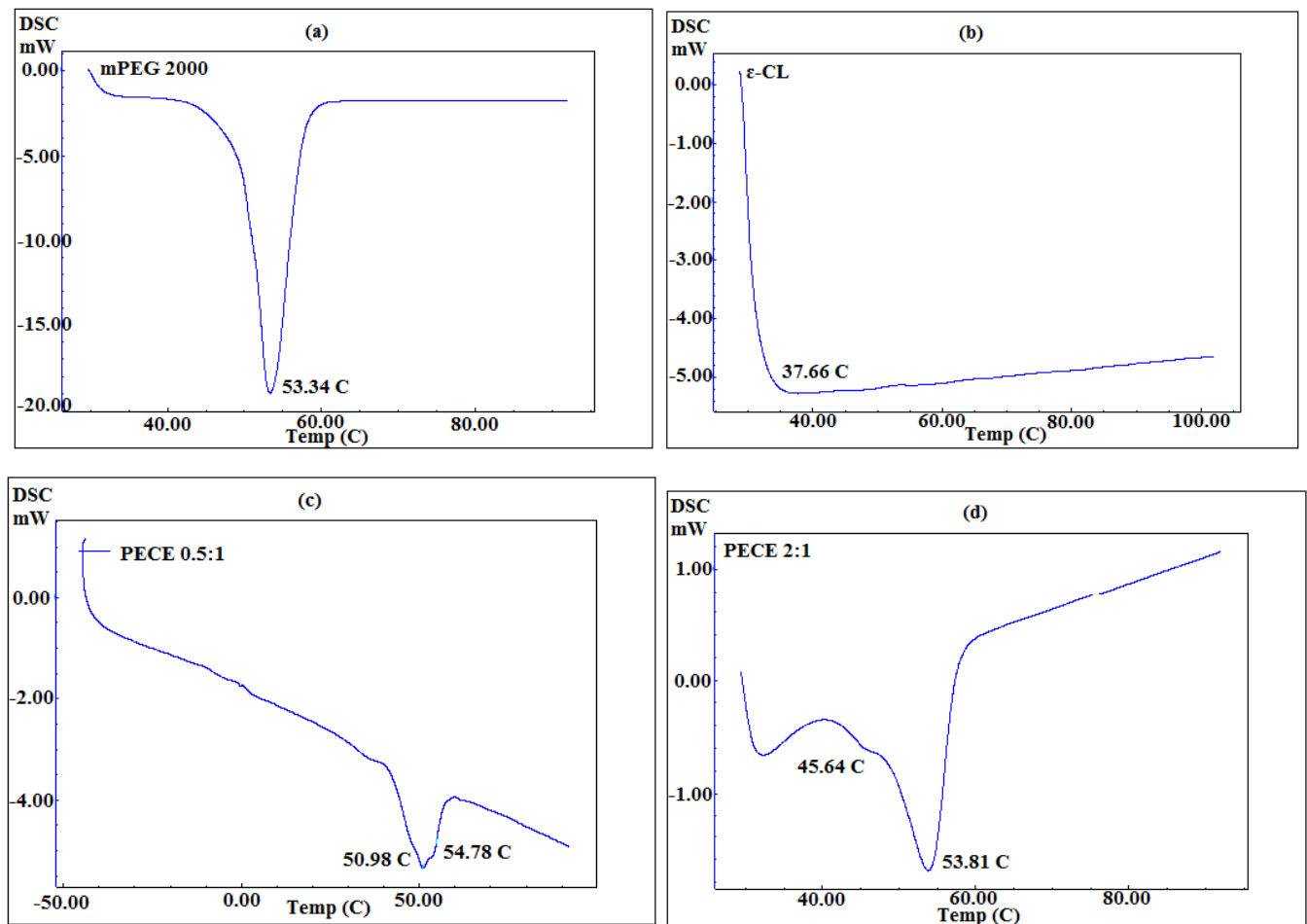

Fig. 3: Analysis thermal of (a). mPEG2000, (b). $\varepsilon$-CL, (c). PECE triblock copolymer 0.5:1, and (d). PECE triblock copolymer 2:1 


\section{Influence of the factors on the responses}

\section{Particle size}

PECE triblock copolymer with PCL/PEG ratio of 2:1 has a smaller particle size compared to the PECE triblock copolymer with a ratio of 0.5:1. A higher PCL composition compared to PEG can decrease the size of the PECE triblock copolymer particles. These results differ from the previous research results that a decrease in the properties of hydrophilicity in a copolymer triblock can increase the particle size [11]. However, it is expressed in other studies that the greater the molecular weight of the PEG in the PECE triblock copolymer can provide a stabilization effect of the colloidal steric on its hydrophiles so that with a low PEG composition can lower the particle size $[6,12]$. Graphic influence ratio of PCL/PEG on particle size can be seen in fig. 4.

Higher of PECE/drug ratio of 40:1 has a smaller particle size than the ratio of 10:1. This is due to the core part of the hydrophobic

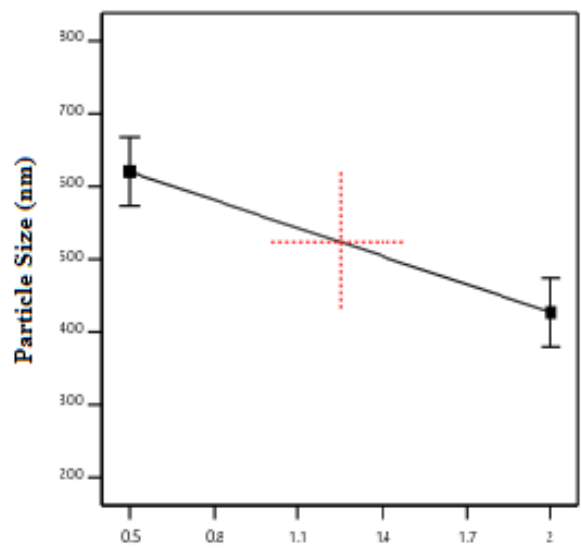

A: PCL/PEG copolymer that is enlarged by the drug that is ensnared by the copolymer [13]. Additionally, an increase in the number of drugs in a limited micelle copolymer may cause adsorption of drug molecules on the outer surface of the micelle core so as to increase the particle size [14]. Graphic influence ratio of PECE/drug on the particle size can be seen in fig. 4 .

The interaction between factors of PCL/PEG ratio and PECE/drug ratio affects the particle size decline. The greater of PCL/PEG ratio and PECE/drug ratio then the resulting particle size is smaller. A greater ratio of PCL/PEG and PECE/drug can reduce particle size by lowering the effects of colloidal steric stability caused by the weight of large PEG molecules and due to the formed micelle copolymer can ensnare drug adequately, respectively $[12,14]$. Effect of interactions between factor ratio of PCL/PEG and $\mathrm{PECE} /$ drug on the particle size response is depicted with a contour plot in fig. 5 .

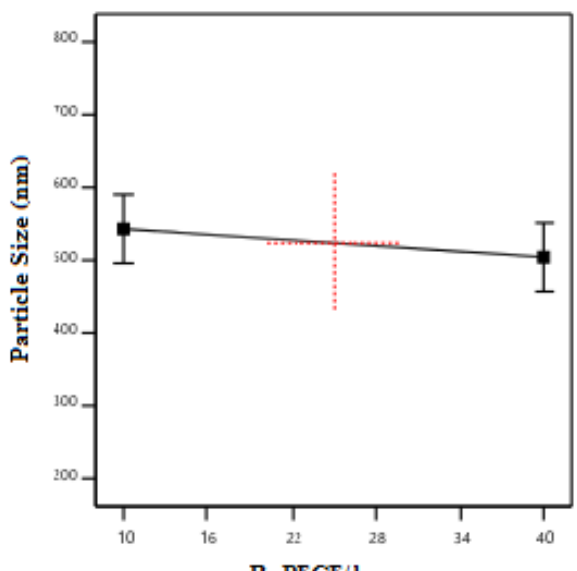

B: PECE/drug

Fig. 4: Graphic influence ratio of PCL/PEG and PECE/drug on the particle size

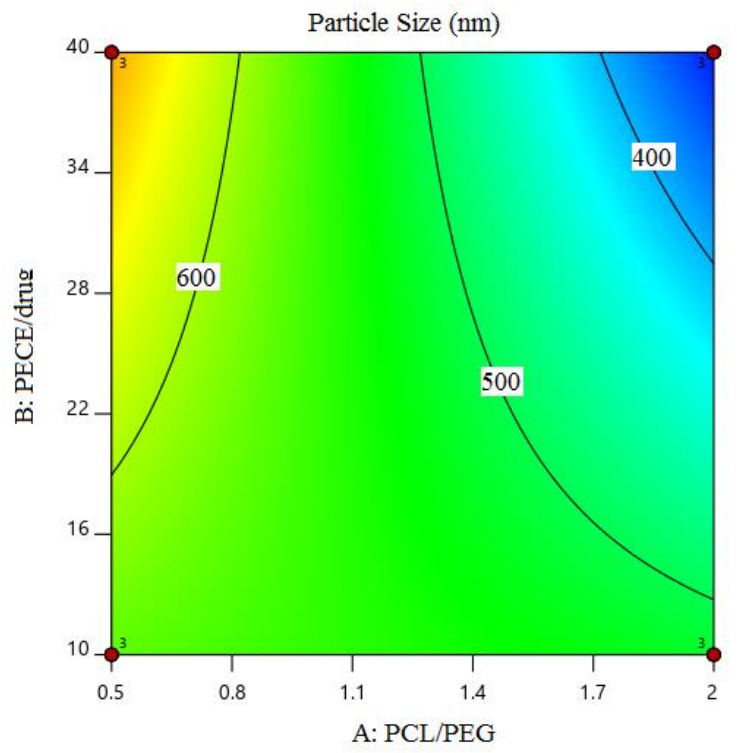

Fig. 5: Contour plot effect of interactions factor ratio of PCL/PEG and PECE/drug on the particle size

\section{Entrapment efficiency (EE)}

PECE triblock copolymer with PCL/PEG ratio of 0.5:1 has a smaller EE compared to PCL: PEG ratio of $2: 1$. The ability to ensnare the drug in a PECE triblock copolymer that has a smaller PCL composition will be decreased. It is related to the increase of the hydrophobic block on the triblock copolymer will increase its interactions with hydrophobic drugs so can increase the ability to ensnare drugs [8]. Graphs the effect of PCL: PEG ratio on the EE can be seen in fig. 6. 

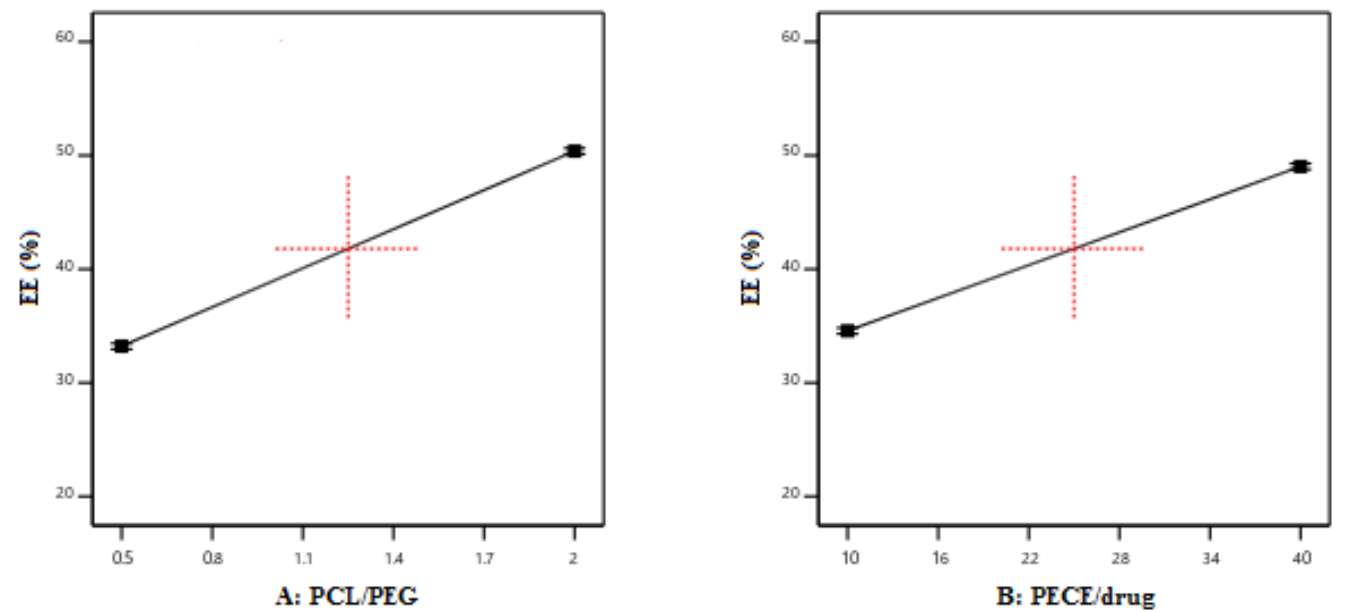

Fig. 6: Graphic influence ratio of PCL/PEG and PECE/drug on the EE

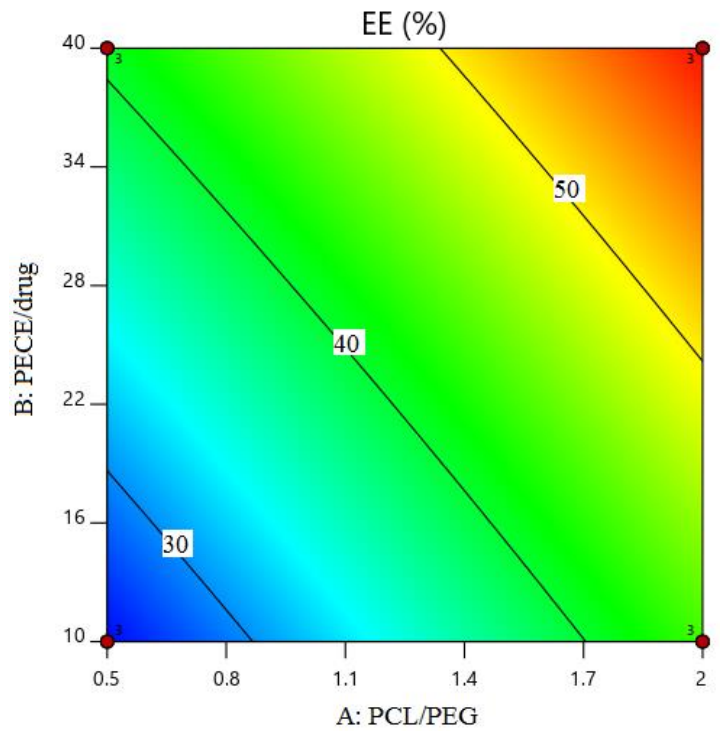

Fig. 7: Contour plot effect of interactions factor ratio of PCL/PEG and PECE/drug on the EE

PECE triblock copolymer with PECE/drug ratio of 10:1 has a smaller EE compared to ratio of 40:1. Larger PECE composition will contain more hydrophobic copolymer blocks so the ability to ensnare hydrophobic drugs will increase. Lower PECE/drug ratio will occur precipitation of drug so EE that is reached also has low. Precipitation of the drug can occur because the core of the micelle is experiencing saturation by the drugs when the number of drugs larger by the number of copolymer. Graphs influences ratio of PECE/drug on the EE can be seen in fig. 6 .

The interaction factors of PCL/PEG ratio and PEG/drug ratio affects on EE decline. The greater of PCL: PEG ratio and PECE/drug ratio can lower the PECE triblock copolymer ability to ensnare the drug. It is possible because in a large ratio to the two factors of the micelle copolymer have suffered saturation so that EE values are constant or can decrease [15]. Contour plot influence of interaction two factors can be seen in fig. 7 .

\section{Solubility}

Drug solubility in the PECE triblock copolymer with PCL/PEG ratio of $2: 1$ greater than in the PCL: PEG ratio of $0.5: 1$. A larger composition ratio is a larger number of PCL, so drug that can be snared in a copolymer will also be greater. In contrast, the smaller PCL/PEG ratio will contain fewer drugs due to the slight number of PCL. Graphs influences the ratio of PCL/PEG on the drug solubility can be seen on the fig. 8 .

PECE/drug ratio of 40:1 more dissolving of the drug than the ratio of $10: 1$ is indicated by the greater value of drug solubility. This is due to the composition of PECE triblock copolymer which more will ensnare more drugs into the micelle copolymer so that the drug will be more dissolved. Graphs influences ratio of PECE/drug on the solubility the drug can be seen in fig. 8 .

The interaction of PCL/PEG ratio and PECE/drug ratio factors has an influence on increased solubility of the drug. The higher PCL/PEG ratio and PECE/drug ratio will increase the drug solubility. The influence of the interaction of both factors on the solubility of the drug according to its influence on each factor. Contour plot influence of interaction two factors on the drug solubility can be seen in fig. 9 . 


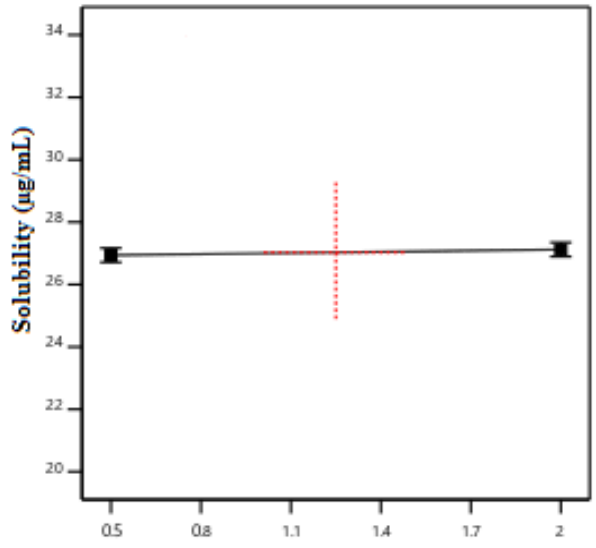

A: PCL/PEG

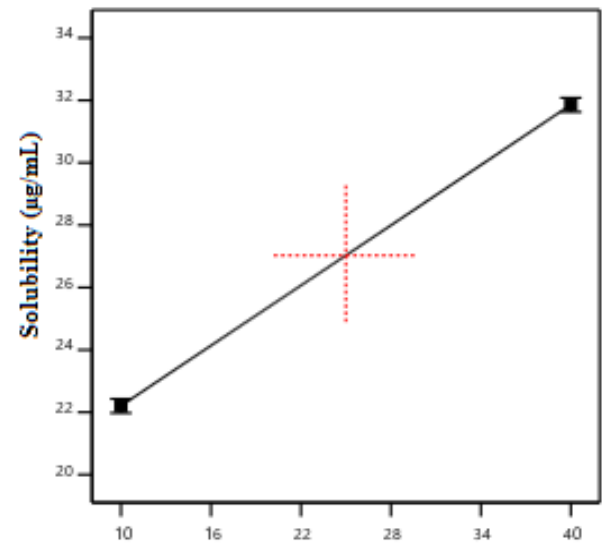

B: PECE/drug

Fig. 8: Graphic influence ratio of PCL/PEG and PECE/drug on the drug solubility

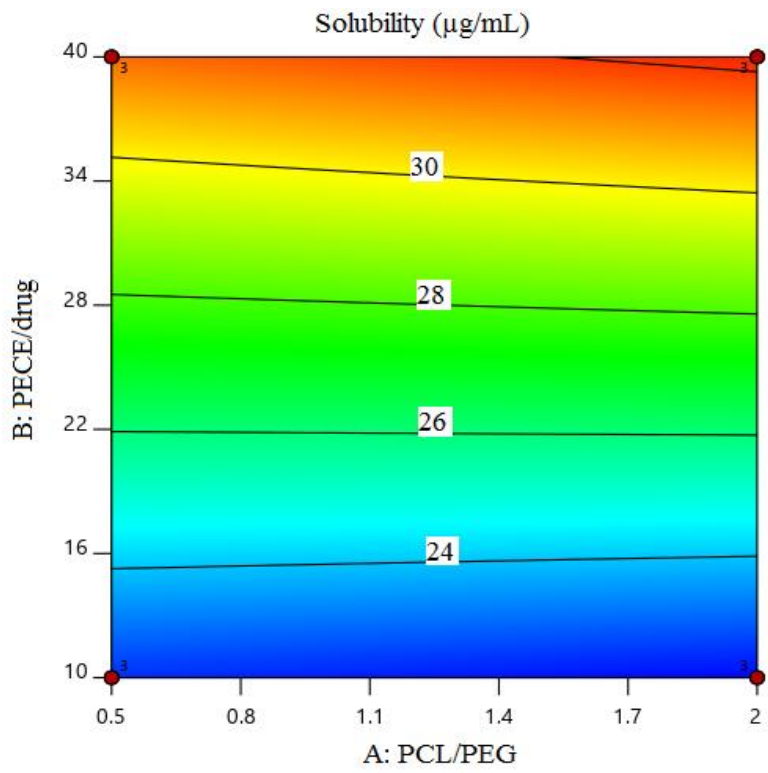

Fig. 9: Contour plot effect of interactions factor ratio of PCL/PEG and PECE/drug on the drug solubility

Table 2: Analysis of variance, parameter fit statistic, and regression coefficient for all responses

\begin{tabular}{|c|c|c|c|}
\hline \multicolumn{4}{|c|}{ Analysis of variance (p-value) } \\
\hline Parameter & Particle size (nm) & EE (\%) & Solubility $(\mu \mathrm{g} / \mathrm{ml})$ \\
\hline Model & 0.0027 & $<0.0001$ & $<0.0001$ \\
\hline A-PCL/PEG & 0.0015 & $<0.0001$ & 0.3796 \\
\hline B-PECE/drug & 0.3706 & $<0.0001$ & $<0.0001$ \\
\hline $\mathrm{AB}$ & 0.0090 & 0.0127 & 0.0159 \\
\hline \multicolumn{4}{|l|}{ Fit Statistic } \\
\hline $\mathrm{R}^{2}$ & 0.8139 & 0.9992 & 0.9967 \\
\hline Adjusted $\mathrm{R}^{2}$ & 0.7441 & 0.9989 & 0.9955 \\
\hline Predicted $\mathrm{R}^{2}$ & 0.5813 & 0.9982 & 0.9926 \\
\hline Adeq Precision & 8.1533 & 139.7987 & 52.2755 \\
\hline \multicolumn{4}{|c|}{ Regression Coefficient } \\
\hline Intercept & 523.62 & 41.80 & 27.03 \\
\hline A-PCL/PEG & -96.87 & 8.58 & 0.0912 \\
\hline B-PECE/drug & -19.43 & 7.23 & 4.83 \\
\hline $\mathrm{AB}$ & -70.18 & -0.3613 & 0.2988 \\
\hline
\end{tabular}

\section{Responses model analysis}

The analysis aims to determine the model mathematically to illustrate the influence of factors on the responses. Result of variance analysis, parameter fit statistic, and regression coefficient for all responses presented in table 2.
Results analysis of variances (ANOVA) indicates that the model for all responses is significant $(\mathrm{p}<0.05)$. The determination coefficient $\left(\mathrm{R}^{2}\right)$ represents the percentage of the model can predict the influence of the factor on a response. This result shows that model on particle size, EE and drug solubility can predict $81.93 \%, 99.92 \%$ 
and $99.67 \%$, respectively. The difference between the Predicted $\mathrm{R}^{2}$ and Adjust $\mathrm{R}^{2}$ values is less than 0.2 and Adeq. Precision value is more than 4 which means that the resulting model can be used to demonstrate the effect of factors on the responses.

This model will explain the influence of factors on the responses with the mathematical equation of the regression coefficient (table 2 ). Coefficients have a positive or negative sign that will illustrate the influence of factor on the responses. A positive sign means that the higher the factor will increase the response, while the negative sign shows that the response will decline as the factor increase (16).

\section{Optimum formula PECE triblock copolymer as drug carrier}

The optimum formula chosen is the formula with the highest desirability value of 0.949 . The optimum formula is the PCL/PEG ratio of 2:1 and PECE/drug ratio of 40:1 with the predictive response of particle size is $337.33 \mathrm{~nm}$, EE is $57.247 \%$, and drug solubility is $32.244 \mu \mathrm{g} / \mathrm{ml}$. Response measurement in optimum formula is done confirmation to know the difference in response value of measurement result with prediction value. Comparison of predicted response value with measurement results presented in table 3.

Table 3: Comparison of predicted response value vs measurement results

\begin{tabular}{|c|c|c|c|}
\hline Responses & Prediction & Measurement & $p$-value \\
\hline \multirow[t]{3}{*}{ Particle size (nm) } & 337,133 & 352,3 & 0,064 \\
\hline & & 351,1 & \\
\hline & & 367,5 & \\
\hline \multirow[t]{3}{*}{ Entrapment Efficiency (EE) } & 57,247 & 57,2466 & 1,000 \\
\hline & & 58,0030 & \\
\hline & & 58,0030 & \\
\hline \multirow[t]{3}{*}{ Drug solubility $(\mu \mathrm{g} / \mathrm{ml})$} & 32,244 & 32,4962 & 0,073 \\
\hline & & 32,5719 & \\
\hline & & 32,8744 & \\
\hline \multirow[t]{3}{*}{ Zeta Potential (mV) } & - & $-21,2$ & - \\
\hline & & $-19,3$ & \\
\hline & & $-16,1$ & \\
\hline
\end{tabular}

The result of the comparison indicate that the all responses have the same value as the predicted value $(\mathrm{p}>0.05)$. the results stated that the optimum formula in this study was confirmed.

\section{CONCLUSION}

The PECE triblock copolymer was preparated using ring-opening polymerization method with $\mathrm{Sn}(\mathrm{Oct})_{2}$ as a catalyst and then continued the reaction with HMDI as coupling agent. Ketoprofen was loaded into PECE triblock copolymer using methods emulsification and solvent evaporation. The optimization study to obtain the optimum formula of PECE triblock copolymer was loaded ketoprofen has been successfully carried out using the full factorial design. The formula optimum selected were ratio of PCL/PEG 2:1 and ratio of PECE/drug 40:1 with characteristic observed particle size is $356,967 \pm 9,142 \mathrm{~nm}$, EE is $57,751 \pm 0,437 \%$, drug solubility is $32,648 \pm 0,200 \mu \mathrm{g} / \mathrm{ml}$ and zeta potential- $18,867 \pm 2,578 \mathrm{mV}$.

\section{AUTHORS CONTRIBUTIONS}

All of the authors listed in these manuscripts have contributed to this research

\section{CONFLICT OF INTERESTS}

The author declares that there is no conflict of interest related to this research.

\section{REFERENCES}

1. Pandey SK, Haldar C, Patel DK, Maiti P. Biodegradable polymers for potential delivery systems for therapeutics. In: Dutta PK, Dutta J. editors. Multifaceted development and application of biopolymers for biology, biomedicine and nanotechnology. Berlin, Heidelberg: Springer Berlin Heidelberg; 2013.

2. Hoang NH, Lim C, Sim T, Oh KT. Triblock copolymers for nanosized drug delivery systems. J Pharm Investigation 2017;47:27-35.

3. Miyata K, Christie RJ, Kataoka K. Polymeric micelles for nanoscale drug delivery. React Funct Polym 2011;71:227-34.

4. Shohin IE, Kulinich JI, Ramenskaya GV, Vasilenko GF. Evaluation of in vitro equivalence for drugs containing BCS class II compound ketoprofen. Dissolution Technol 2011;18:26-9.

5. Gong C, Shi S, Dong P, Kan B, Gou M, Wang X, et al. Synthesis and characterization of PEG-PCL-PEG thermosensitive hydrogel. Int J Pharm 2009;365:89-99.

6. Fares AR, ElMeshad AN, Kassem MAA. Enhancement of dissolution and oral bioavailability of lacidipine via pluronic
P123/F127 mixed polymeric micelles: formulation, optimization using central composite design and in vivo bioavailability study. Drug Delivery 2018;25:132-42.

7. Sayed S, Habib BA, Elsayed GM. Tri-block co-polymer nanocarriers for enhancement of oral delivery of felodipine: preparation, characterization and permeation. J Liposome Res 2018;28:182-92.

8. Cuong NV, Hsieh MF, Chen YT, Liau I. Synthesis and characterization of PEG-PCL-PEG triblock copolymers as carriers of doxorubicin for the treatment of breast cancer. J Appl Polymer Sci 2010;117:3694-703.

9. Stuart BH. Infrared spectroscopy: fundamentals and applications. John Wiley and Sons, London UK; 2004. p. 113-36.

10. Menczel JD, Prime RB. editors. Thermal Analysis of Polymers: Fundamentals and Applications. Hoboken, NJ: Wiley; 2009. p. 688.

11. Colzani B, Speranza G, Dorati R, Conti B, Modena T, Bruni G, et al. Design of smart GE11-PLGA/PEG-PLGA blend nanoparticulate platforms for parenteral administration of hydrophilic macromolecular drugs: synthesis, preparation and in vitro/ex vivo characterization. Int J Pharm 2016;511:111223.

12. Wei Z, Hao J, Yuan S, Li Y, Juan W, Sha X, et al. Paclitaxel-loaded pluronic P123/F127 mixed polymeric micelles: formulation optimization and in vitro characterization. Int $\mathrm{J}$ Pharm 2009;376:176-85.

13. Kulthe SS, Inamdar NN, Choudhari YM, Shirolikar SM, Borde LC, Mourya VK. Mixed micelle formation with hydrophobic and hydrophilic pluronic block copolymers: implications for controlled and targeted drug delivery. Colloids Surf B 2011;88:691-6.

14. Rupp C, Steckel H, Müller BW. Solubilization of poorly watersoluble drugs by mixed micelles based on hydrogenated phosphatidylcholine. Int J Pharm 2010;395:272-80.

15. Mu CF, Balakrishnan P, Cui FD, Yin YM, Lee YB, Choi HG, et al. The effects of mixed MPEG-PLA/Pluronic $®$ copolymer micelles on the bioavailability and multidrug resistance of docetaxel. Biomaterials 2010;31:2371-9.

16. Azouz L, Dahmoune F, Rezgui F, G’Sell C. Full factorial design optimization of anti-inflammatory drug release by PCL-PEGPCL microspheres. Mater Sci Eng 2016;58:412-9. 